\title{
Studi berbagai jenis sarang permanen untuk mengembangbiakkan semut hitam, Dolichoderus thoracicus (Smith) (Hymenoptera: Formicidae)
}

\author{
Study of various types of permanent nest to propagate \\ the black ants, Dolichoderus thoracicus (Smith) \\ (Hymenoptera: Formicidae)
}

\author{
Ahmad Saleh* \\ Bah Lias Research Station, PT. PP. London Sumatra Indonesia Tbk. \\ Jalan Jendral A. Yani No.2, PO Box 1154, Medan 20111
}

(diterima Mei 2012, disetujui Agustus 2012)

\begin{abstract}
ABSTRAK
Semut hitam Dolichoderus thoracicus (Smith) (Hymenoptera: Formicidae) merupakan salah satu agens hayati yang dapat digunakan untuk mengendalikan hama penggerek buah kakao Conopomorpha cramerella dan Helopeltis sp. Di dalam aplikasinya, diperlukan populasi semut hitam yang tinggi untuk secara efektif mencegah serangan $C$. cramerella, sehingga untuk mengembangkan populasi semut harus membuat sarang semut di perkebunan. Kepadatan populasi semut hitam pada tiga jenis sarang permanen dan satu sarang tidak permanen diamati perkembanganya selama 3 bulan. Setiap bulan, lima sarang dari masing-masing jenis diambil secara acak kemudian dihitung semua fase semut hitam yang berada di dalam sarang. Sarang permanen akan menyangga kepadatan populasi semut selama beberapa tahun dan kepadatan populasi semut hitam lebih tinggi bila dibandingkan dengan sarang yang terbuat dari daun kakao kering saja. Sarang permanen terbuat dari 75 lembar daun kakao kering yang dimasukkan ke dalam kantong plastik yang sudah diberi lubang ventilasi. Dalam jangka panjang sarang semut hitam permanen biayanya lebih ekonomis dibandingkan sarang semut yang dibuat hanya dari daun kakao kering karena tidak selalu diperlukan pergantian. Sarang semut permanen juga akan menjamin mempertahankan kepadatan populasi semut hitam stabil.
\end{abstract}

Kata kunci: Dolichoderus thoracicus, sarang permanen, sarang tidak permanen, daun kakao, kantong poliester

\begin{abstract}
Black ants, Dolichoderus thoracicus (Smith) (Hymenoptera: Formicidae) is one of the biological agents that can be used to control the cocoa pod borer Conopomorpha cramerella and Helopeltis sp. To effectively prevent $C$. cramerella infestation, high population of black ants are required. Population growth of black ants in three types of permanent nests and non permanent nest were observed during 3 months. Every month, five nests of each type were taken at random and then all stadia were calculated. The permanent nests will support ant population for some years and the black ant population per nest is higher when compared to nest made of dried cocoa leaves only. Permanent nests are made of 75 pieces of dried cocoa leaves which are placed in plastic bags with ventilation holes. In the longer term permanent black ant nests are more cost effective then ant nests which have been made from only dried leaves because frequent replacement is not required. Permanent ant nests will also ensure a stable black ant population is maintained.
\end{abstract}

Key words: Dolichoderus thoracicus, permanent nest, non permanent nest, cocoa leaves, polyester bag

\footnotetext{
*Penulis korespondensi: Ahmad Saleh. Bah Lias Research Station, PT. PP. London Sumatra Indonesia Tbk 


\section{PENDAHULUAN}

Hama penggerek buah kakao (PBK) Conopomorpha cramerella Snellen (Lepidoptera: Gracillaridae) dan Helopeltis sp. (Miller) (Hemiptera: Miridae) adalah hama yang serius di perkebunan kakao PT. London Sumatra Indonesia Tbk (Lonsum) dan pada tanaman kakao umumnya. Serangan hama PBK dapat menurunkan produksi mencapai 60-80\% (Wardojo 1980), sedangkan hama Helopeltis sp. menurunkan produksi sekitar 36-75\% (Wardojo 1988).

Semut hitam, Dolichoderus thoracicus (Smith) (Hymenoptera; Formicidae) diketahui sebagai agen pengendali hayati hama PBK (Ho \& Khoo 1994; See \& Khoo 1996; Saleh 2003) dan Helopeltis sp. (Bakri et al. 1986; Way \& Khoo 1989a; Giesberger 1993; Saleh \& Abu Hassan 2001).

Semut hitam telah dikembangkan secara komersial di kebun-kebun kakao Lonsum di Sumatera sejak tahun 1983 (Bakri et al. 1986; Graham 1991; Syed \& Saleh 1991; Saleh \& Abu Hassan 2001). Di kebun kakao Treblasala, Jawa timur, penggunaan kimia untuk pengendalian Helopeltis dan PBK sangat rendah atau terbatas pada areal yang belum menghasilkan kerena semut hitam telah berkembang (Sulistyowati et al. 2006).

Populasi semut hitam yang tinggi diperlukan untuk mengendalikan serangan PBK secara efektif, disertai dengan panen sering dan penguburan kulit buah kakao (Ho 1994; Saleh et al. 2006). Saleh dan Abu Hassan (2001) mengamati bahwa populasi semut hitam yang stabil dan dapat mengendalikan PBK bila lebih dari $70 \%$ buah kakao yang dipanen terdapat kutu putih. Semut hitam, D. thoracicus hidup bersimbiosis dengan kutu putih Cataenococcus hispidus (Morrison) (Homoptera: Pseudococcidae) (Ho \& Khoo 1997).

Sarang semut hitam yang digunakan di perkebunan kakao Lonsum adalah sarang yang dibuat dari 75 lembar daun kakao kering yang diikat dengan tali plastik. Sarang ini hanya dapat bertahan sekitar 1 tahun dan harus diganti dengan sarang baru untuk mempertahankan kestabilan kepadatan populasi semut hitam. Keberadaan sarang semut buatan yang baik pada tanaman kakao sangat menentukan kestabilan kepadatan populasi semut hitam pada areal kakao (Saleh 2003; Saleh et al. 2006).
Penelitian ini bertujuan untuk mempelajari keefektifan dari berbagai jenis sarang semut buatan yang dapat bertahan lama dan ekonomis.

\section{BAHAN DAN METODE}

\section{Lokasi penelitian}

Penelitian dilaksanakan pada bulan Januari sampai April 2010 di Perkebunan Bah Lias, dan Bah Lias Research Station (BLRS) PT Lonsum di Kabupaten Simalungun, Sumatera Utara, 99 $15^{\prime} 36^{\prime \prime}-99^{\circ} 21^{\prime} 36^{\prime \prime}$ Bujur Timur dan 3०8'24"3'13'24" Lintang Selatan dengan ketinggian $32 \mathrm{~m}$ diatas permukaan laut. Data meteorologi tahun 2010 tercatat, curah hujan pertahun 1.786 $\mathrm{mm}$, rata-rata temperatur $27,35^{\circ} \mathrm{C}$ dan kelembaban $85 \%$.

\section{Persiapan berbagai media untuk sarang semut}

Pengamatan kepadatan populasi semut hitam pada empat jenis sarang dilakukan pada klon kakao yang ditanam pada tahun 1984 dengan kerapatan saat ini 550 pohon per ha. Sebagai naungan adalah tanaman kelapa dengan kerapatan 38 pohon/ha. Empat jenis sarang semut yang diamati terdiri dari satu sarang tidak permanen dan tiga sarang permanen. Sarang yang tidak permanen dibuat dari 75 lembar daun kakao kering (DKK) dan pada bagian atas ditutup dengan dua lembar daun kakao kering kemudian diikat dengan tali plastik (Gambar 1a). Sarang permanen terdiri dari: (i). Sarang dibuat dengan memasukkan 75 lembar daun kakao kering ke dalam kantong poliester (KP) berukuran $35 \mathrm{~cm}$ x $40 \mathrm{~cm}$ x $0.02 \mathrm{~mm}$ dan diberi lubang ventilasi sebanyak 30-40 (Gambar 1b), (ii). Sarang dibuat dengan memasukkan susunan 75 lembar daun kakao kering ke dalam kantong plastik putih yang transparan (KPP) berukuran $36 \mathrm{~cm} \times 50 \mathrm{~cm} \times 0.02$ $\mathrm{mm}$ yang diberi lubang ventilasi 40-50 (Gambar 1c), dan (iii). Sarang dibuat dengan memasukkan susunan 75 lembar daun kakao kering ke dalam kantong plastik hitam (KPH), biasa dipakai untuk pembibitan kelapa sawit berukuran $20 \mathrm{~cm}$ x $50 \mathrm{~cm}$ $\mathrm{x} 0.2 \mathrm{~mm}$ dan mempunyai lobang ventilasi \pm 50 (Gambar 1d).

\section{Penempatan sarang semut}

Lima belas pohon dipilih secara acak pada areal kakao 2 ha yang ada populasi semut hitam. 
Pada setiap pohon diletakkan masing-masing satu sarang dari keempat jenis pada cabang-cabang pohon kakao, sehingga jumlah setiap jenis sarang adalah 15. Kepadatan populasi semut dari setiap jenis sarang dihitung pada waktu satu, dua dan tiga bulan setelah diletakkan pada pohon kakao. Setiap pengamatan diambil 5 sarang semut dari masingmasing jenis secara acak dan dimasukkan kedalam kantong plastik $(50 \mathrm{~cm}$ x $60 \mathrm{~cm})$ yang terpisah, kemudian dibawa ke insektari dan dimasukkan ke dalam lemari es. Semua stadium semut (telur, larva, pupa dan dewasa) dihitung dan dicatat sesuai dengan jenis sarang, 5 sarang dari masing-masing jenis (sebagai ulangan), dan waktu pengamatan.

\section{Analisis statistik}

Pengambilan sampel empat jenis sarang diulang lima kali dan percobaan disusun dalam rancangan acak kelompok (RAK). Data percobaan diolah dengan analisis varian satu jalur dengan program GenStat Edisi 14. Pembedaan kepadatan populasi semut diantara sarang, dilakukan dengan uji beda jarak terkecil (LSD).

\section{HASIL}

Dari hasil setiap pengamatan, terlihat kepadatan populasi semut hitam bervariasi pada keempat sarang yang dicoba. Kepadatan populasi semut hitam meningkat dalam semua sarang permanen dan berbeda nyata dengan kepadatan populasi semut hitam di dalam sarang tidak permanen yang dibuat dari daun kakao kering, DKK (pada bulan pertama; $\mathrm{P}<0,031$, bulan kedua; $\mathrm{P}<0,007$ dan bulan ketiga; $\mathrm{P}<0,001)$. Sebaliknya, kepadatan populasi semut hitam pada sarang tidak permanen (DKK) menurun pada bulan pengamatan kedua dan ketiga. Kepadatan populasi semut hitam tidak berbeda nyata di antara sarang permanen pada ketiga bulan pengamatan (Gambar 2 dan Tabel 1, 2 dan 3).

Pada satu bulan pertama pengamatan sudah terdapat variasi kepadatan populasi semut hitam di dalam setiap jenis sarang. Kepadatan populasi semut terbanyak terdapat pada sarang semut dari kantong plastik hitam (KPH) 39.769 individu diikuti dengan sarang semut dari kantong poliester
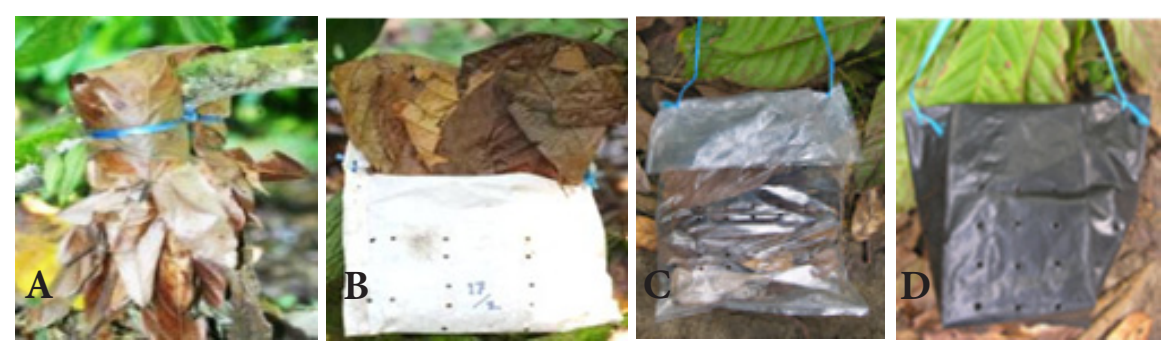

Gambar 1. Berbagai bahan sarang semut hitam Dolichoderus thoracicus. A: sarang tidak permanen dari daun kakao kering (DKK); B: sarang permanen dari kantong polyester (KP); C: kantong plastik putih (KPP); dan D: kantong plastik hitam (KPH).

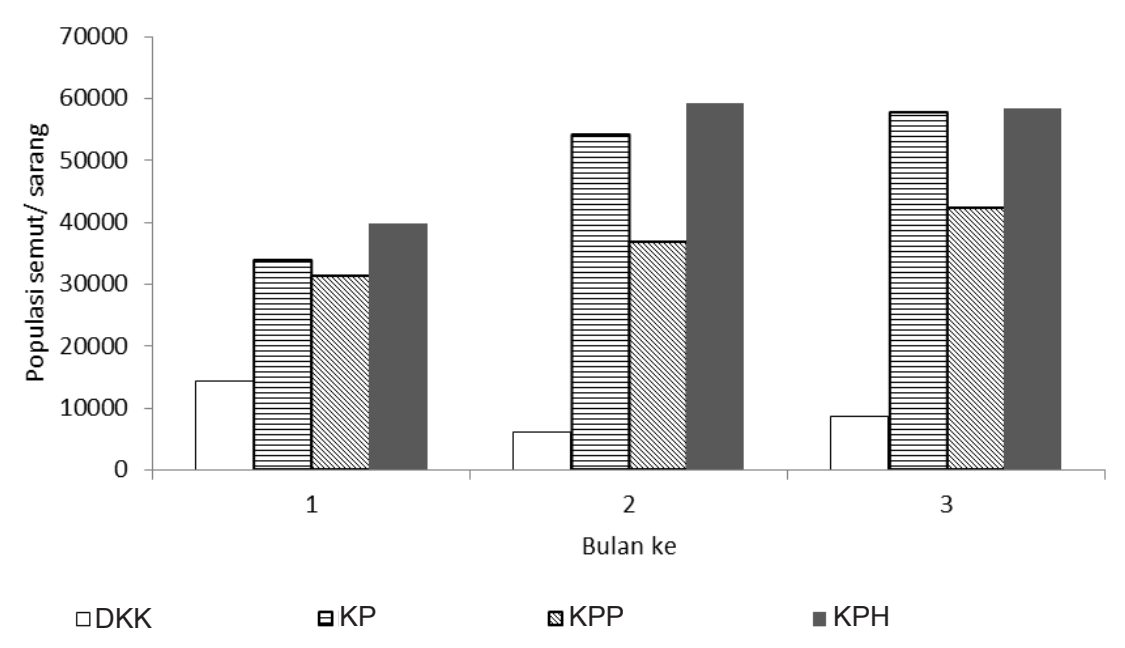

Gambar 2. Populasi semut hitam dalam jenis sarang yang berbeda pada tiga bulan pengamatan. 

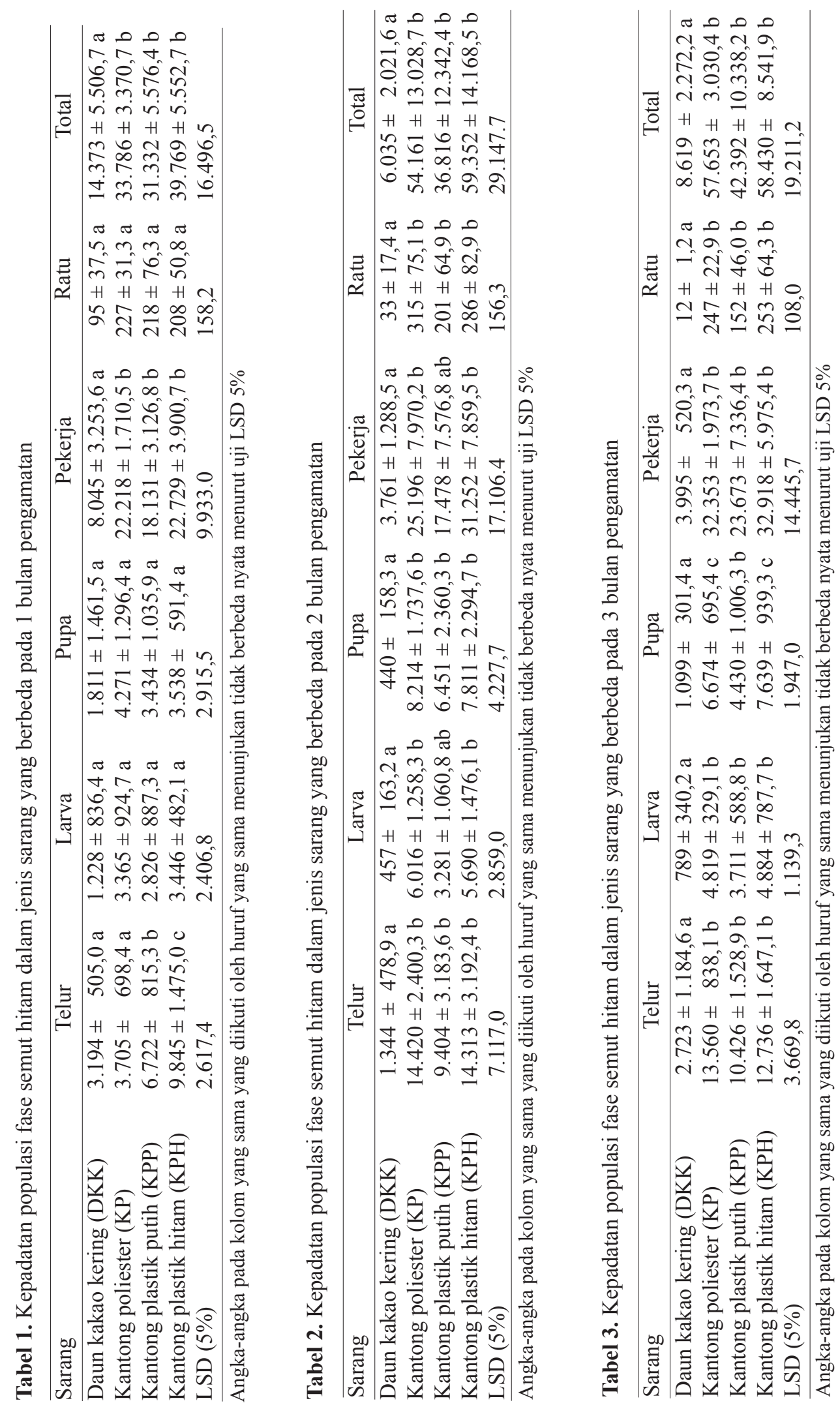
(KP) 33.786 individu dan sarang semut dari kantong plastik putih (KPP) 31.332 individu dan yang terendah pada sarang daun kakao kering (DKK) 14.373 individu. Total fase larva, pupa dan ratu tidak berbeda nyata pada semua jenis sarang, sedangkan total stadium pekerja sangat berbeda di antara sarang tidak permanen dengan sarang permanen, tetapi stadium telur tidak berbeda nyata di antara sarang DKK dengan KP (Tabel 1).

Kepadatan populasi semut meningkat pada tiga jenis sarang permanen KPH (59.352 individu), KP (54.161 individu) dan KPP (36.352 individu), sedangkan total semut pada sarang tidak permanen DKK (6.035 individu) menurun pada bulan kedua pengamatan. Jumlah fase telur, larva, pupa dan ratu semut hitam sangat berbeda di antara sarang yang permanen dan tidak permanen (DKK) kecuali stadium larva dan pekerja pada sarang permanen KPP (Tabel 2) .

Pada Tabel 3 menunjukkan bahwa pada bulan ketiga terlihat kepadatan populasi semut hitam pada sarang yang terbuat dari KP (57.653 individu), KPP (42.392 individu) dan DKK (8.619 individu) meningkat dari pengamatan sebelumnya kecuali total semut pada sarang KPH (58.430 individu). Walaupun begitu perbedaan di antara total semua stadium semut pada sarang DKK jauh lebih rendah dibandingkan dengan jenis sarang lainnya.

\section{PEMBAHASAN}

Semut hitam menyenangi sarang permanen yang terbuat dari susunan daun kering kakao yang dimasukan ke dalam kantong poliester, plastik hitam dan plastik putih sehingga kepadatan populasinya 2 kali lebih tinggi dari kepadatan populasi semut di dalam sarang daun kakao (tidak permanen). Semut hitam lebih menyukai pada sarang permanen kerena kondisi di dalam sarang berongga dan teduh (Kalshoven 1981; Saleh et al. 2006). Semut hitam bersarang secara alamiah di antara helaian daun-daun, pelepah daun yang berada di atas pohon (Attygalle et al. 1998; Graham 1991; Delabie et al. 2007) dan dapat juga bersarang pada lipatan daun, seludang bunga kelapa (Kalshoven 1981), sehingga pada tanaman kakao yang mempunyai pelindung kelapa, semut hitam mudah berkembang dan stabil (Way \& Khoo 1989b). Sarang buatan sangat berguna dalam pengembangan semut hitam (Kheong 1999; Saleh et al. 2006) selain itu berfungsi menstabilkan populasi yang diperlukan dalam pengendalian hama PBK (Saleh 2003; Saleh et al. 2006). Walaupun begitu populasi selalu berfluktuasi bergantung dari pada ketersediaan makanan, musuh alami, lingkungan dan iklim (Way \& Khoo 1989b; Ho \& Khoo 1994).

Kepadatan populasi total semut pada sarang permanen tidak berbeda nyata diataranya pada pengamatan bulan pertama hingga ke tiga. Hal ini disebabkan kondisi di dalam sarang permanen sama yaitu susunan lembaran daun kakao yang kering dan berongga di antara susunan daun. Selain itu menunjukan bahwa bahan kantong yang dipakai tidak mempengaruhi suhu di dalam kantong sarang kerena dibuat lobang ventilasi yang cukup. Saleh (2011) menambahkan bahwa sarang permanen yang terbuat dari susunan daun kakao kering di dalam kantong poliester bertahan lebih dari 4 tahun dan kepadatan populasi semut stabil (Lampiran 1a) dan daun tidak mengalami pelapukan (Lampiran 1b), sedangkan sarang yang terbuat dari daun kakao kering hanya bertahan 1 tahun bila menggunakan tali plastik yang berkualitas baik tetapi daun akan rapuh karena terkena hujan dan panas matahari (Lampiran 2).

Sarang semut hitam permanen yang terbuat dari kantong plastik hitam (KPH) dan kantong plastik putih (KPP) dapat direkomendasikan dipakai secara komersil kerena harganya lebih ekonomis.

\section{KESIMPULAN}

Kepadatan populasi semut hitam pada 3 jenis sarang semut permanen lebih tinggi dari sarang semut tidak permanen.

Dalam jangka panjang sarang semut hitam permanen biayanya lebih ekonomis dibandingkan sarang semut yang dibuat hanya dari daun kakao kering karena tidak selalu diperlukan pergantian. Sarang semut permanen juga akan menjamin mempertahankan kepadatan populasi semut hitam stabil. 


\section{UCAPAN TERIMA KASIH}

Penulis mengucapkan terima kasih kepada Dewan Direksi PT.PP. London Sumatra Indoensia Tbk yang telah memberi izin untuk mempublikasi tulisan ini dan kepada Dr. S. Nelson sebagai direktur BLRS yang telah memberi saran dan dukungan.

\section{DAFTAR PUSTAKA}

Attygalle AB, Mutti A, Rohe W, Maschwitz U, Garbe W, Bestmann HJ. 1998. Trail pheromone from the pavan gland of the ant Dolichoderus thoracicus (Smith). Naturwissenschaften 85: 275-277. http:// dx.doi.org/10.1007/s001140050498.

Bakri AH, Asid M, Redshaw MJ. 1986. Pemberantasan Helopeltis secara terpadu dengan penggunaan semut hitam dan bahan kimia pada tanaman coklat di Sumatera Utara. (Using black ants and chemicals in an integrated approach to control Helopeltis in cocoa in North Sumatera). In: Kumpulan Makalah: Temu Ilmiah Entomologi Perkebunan Indonesia (Medan, 22-24 April 1986). pp. 11. Medan: PEI Medan.

Delabie J HC, Jahyny B, Nascimento IC, Mariano CSF, Lacau S, Campiolo, Philpott SM, Leponce M. 2007. Contribution of cocoa plantations to the conservation of native ants (Insecta: Hymenoptera: Formicidae) with a special emphasis on the atlantic forest fauna of Southern Bahia, Brazil. Biodivers Conserv 16:2359-2384. http://dx.doi.org/10.1007/s10531-007-9190-6.

Giesberger G. 1993. Biological control of the Helopeltis pest of cocoa in Java. In: Indranada HTK et al. (Eds.), Guide Book, Theobromae. International Conference on Cocoa Economy. (Bali, 19-21 October 1993). pp. 38-54. Bali: Askindo.

Graham MK. 1991. Biological control of Helopeltis sp. in mature cocoa by the black ant (Dolichoderus bituberculatus) and the cocoa mealybug (Planococcus lilacinus). The Planter 67:543-546.

Ho CT. 1994. Relationship between black cocoa ant, Dolichoderus thoracicus (Hymenoptera: Formicidae) abundance and cocoa pod borer, Conopomorpha cramerella (Lepidoptera: Gracillariidae) damage in a cocoa plantation. In: A Rajan, YB Ibrahim (Eds.), Proceedings of $4^{\text {th }}$ International Plant Protection in Tropics (Kuala Lumpur, 28-31 March 1994). pp. 214-215. Kuala Lumpur: Malaysian Plan Protection Society.
Ho CT, Khoo KC. 1994. Some factors influencing sustenance of high activity of black cocoa ant, Dolichoderus thoracicus (Hymenoptera: Formicidae) in cocoa estates. In: A Rajan \& YB Ibrahim (Eds.), Proceedings of the $4^{\text {th }}$ International Plant Protection in the Tropics (Kuala Lumpur, 28-31 March 1994). pp. 218-220. Kuala Lumpur: Malaysian Plant Protection.

Ho CT, Khoo KC. 1997. Partners in biological control of cocoa pests: mutualism between Dolichoderus thoracicus (Hymenoptera: Formididae and Cataenococcus hispidus (Hemiptera: Pseudococcidae). Bulletin of Entomological Research 87:461-470. http://dx.doi.org/10.1017/ S0007485300041328.

Kalshoven LGE. 1981. Pests of crops in Indonesia. Revised by Van der Laan PA. Jakarta: PT. Ichtiar Baru-van Houve. Translation of: Deplagen van de Cultuurgewasen in Indonesie.

Kheong LV. 1999. Spatial and temporal distribution of Dolichoderus thoracicus Smith in a cocoacoconut agro ecosystem. M.Sc. Thesis. Pulau Pinang: Universiti Sains Malaysia.

Saleh A. 2003. Distribution of cocoa pod borer $(C P B)$, Conopomorpha cramerella (Snellen) and potential of using cocoa black ant (CBA), Dolichoderus thoracicus (Smith) and cocoa mealybugs (CM), Cataenococcus hispidus (Morrison) as biological control agent in Lonsum estates, North Sumatera Indonesia. M.Sc. Thesis. Pulau Pinang: Universiti Sains Malaysia.

Saleh A. 2011. Establishment of the biological control system by black ant, Dolichoderus thoracicus (Smith) (Hymenoptera: Formicidae) and mealybug, Cataenococcus hispidus (Morrison) (Homoptera: Pseudococcidae) against the cocoa pod borer, Conopomorpha cramerella (Snellen) (Lepidoptera: Gracillariidae) in North Sumatera Indonesia. PhD. Thesis. Pulau Pinang: Universiti Sains Malaysia.

Saleh A, Abu Hassan A. 2001. The control of cocoa pod borer (Conopomorpha cramerella) and cocoa mirid (Helopeltis theobromae) by using insecticide and black ant in Lonsum Estates, North Sumatera, Indonesia. In: The $4^{\text {th }}$ Asia Pacific Conference of Entomology (Kuala Lumpur, 14-17 August 2001). pp. 4. Kuala Lumpur: Malaysian Plant Protection Society and Entomological Society of Malaysia.

Saleh A, Abu Hassan A, Che Salmah MR. 2006. Establishment of Dolichoderus thoracicus (Smith) to control Helopeltis theobromae Miller and Conopomorpha cramerella (Snellen) in 
Lonsum cocoa pantations Indonesia. In: IMT-GT Conference (Medan, 22-23 June 2006). pp. 5. Medan: Fakultas Pertanian USU Medan.

See YA, Khoo KC. 1996. Influence of Dolichoderus thoracicus (Hymenoptera: Formicidae) on cocoa pod damage by Conopomorpha cramerella (Lepidoptera: Gracillariidae) in Malaysia. Buletin of Entomological Research 86:467-474.

Sulistyowati E, Mufriati E, Andayani B. 2006. Pengaruh samping aplikasi Paecilomyces fumosoroseus terhadap semuthitam, Dolichoderus thoracicus, predator Helopeltis antonii dan penggerek buah kakao. Pelita Perkebunan 22:91100.

Syed RA, Saleh A. 1991. Integrated control on insect pests of cocoa in PT. PP. London Sumatera Indonesia Tbk plantation in Indonesia. In: Tay EB (Ed.), Proc, $19914^{\text {th }}$ International Cocoa Conference (Kuala Lumpur, 25-28 September 1994). pp. 638. Kuala Lumpur: Malaysian Cocoa Board.
Wardojo S. 1980. The cocoa pod borer-a major hindrance to cocoa development. Indonesia Agriculture Research and Development 2:2-4.

Wardojo S. 1992. Major pest and diseases of cocoa in Indonesia. In: keane PJ, Putter CAJ (Eds.), Cocoa Pest and Diseases Management in Southeast Asia and Australia. pp. 63-68. Rome: Food and Agriculture Organization of The United Nations.

Way, MJ, Khoo KC. 1989a. Relationship between Helopeltis theobromae damage and ants with special reference to Malaysian cocoa smallholding. Journal of Plant Protection in the Tropics 6:1-11.

Way, MJ, Khoo KC. 1989b. Colony dispersion and nesting habits of the ants, Dolichoderus thoracicus and Oecophylla Smaragdina (Hymenoptera: Formicidae), in relation to their success as biological control agents on cocoa. Bulletin of Entomological Research 81:341-350.

\section{LAMPIRAN GAMBAR}

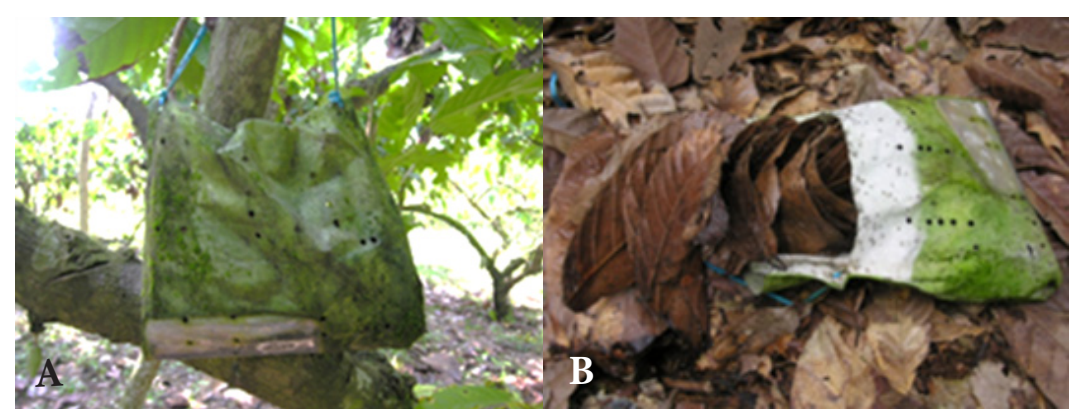

Lampiran 1. Kondisi sarang semut dari kantong poliester setelah 4 tahun. A: kondisi kantong poliester, B: kondisi daun kakao.

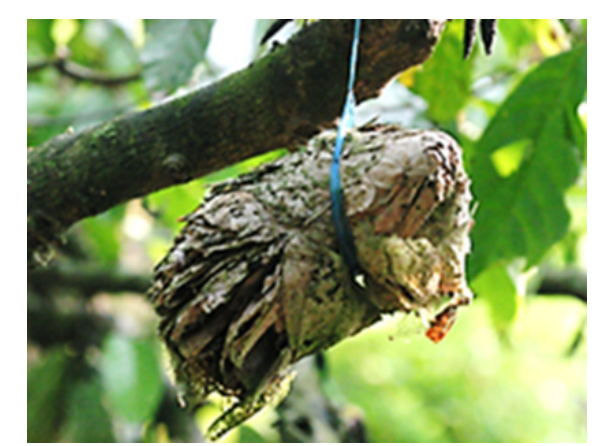

Lampiran 2. Kondisi sarang daun kakao setelah 1 tahun. 